\title{
Laryngeal Tube Suction-D, Combitube, and Proseal Laryngeal Mask Airway: Randomized Clinical Trial
}

\author{
Davide Cattano ${ }^{1 *}$, Lara Ferrario', Chirag B. Patel ${ }^{1}$, Katherine C. Normand ${ }^{1}$, Carmen Seitan ${ }^{1}$ and Carin A. Hagberg ${ }^{1}$ \\ Correspondence: Davide.Cattano@uth.tmc.edu \\ 'Department of Anesthesiology, University of Texas Medical School at Houston, Texas, USA.
}

\begin{abstract}
Background: The Esophageal Tracheal CombitubeTM (ETC), Disposable Laryngeal Tube SuctionTM (LTS-D), and ProSeal Laryngeal Mask AirwayTM (PLMA) are devices that can secure the airway and maintain access to the stomach in at-risk patients, such as trauma or non fastened patients, when endotracheal intubation is difficult or impossible.

Methods: We conducted a randomized controlled trial with the following primary endpoints: duration of intubation, successful placement on first attempt, leak pressures, and post-operative morbidity (dysphagia, sore throat).

Results: The ETC ( $n=71)$, LTS-D ( $n=73)$, and PLMA $(n=72)$ groups showed significant differences in the likelihood of successful insertion on first attempt $(70.0 \%, 89.0 \%$, and $72.2 \%$, respectively), $p=0.012$. There was no significant difference in successful insertion rate among the ETC (90.1\%), LTS-D (94.5\%), and PLMA (93.1\%) groups, $\mathrm{p}=0.6$. Cuff pressure was significantly greater in the ETC group $\left(284.2 \pm 63.0 \mathrm{~cm} \mathrm{H}_{2} \mathrm{O}\right)$ compared to each of the LTS-D $\left(72.0 \pm 15.7 \mathrm{~cm} \mathrm{H}_{2} \mathrm{O}\right)$, and PLMA $\left(72.3 \pm 21.7 \mathrm{~cm} \mathrm{H} \mathrm{H}_{2} \mathrm{O}\right) \mathrm{groups}$, $\mathrm{p}<0.00001$. Cuff volume was significantly greater in the ETC group ( $84.0 \pm 9.1 \mathrm{cc})$ compared to each of the LTS-D (64.8 $\pm 12.4 \mathrm{cC})$ and PLMA $(31.3 \pm 17.9 \mathrm{cc})$ groups, $\mathrm{p}<0.00001$, and was significantly greater in the LTS-D group compared to the PLMA group, $\mathrm{p}<0.00001$. Prevalence of severe sore throat and dysphagia was greater in the ETC group compared to the other groups, both at 2 hours $(p<0.003)$ and 24 hours $(p<0.0001)$ after securing the airway.

Conclusion: The ETC is an airway device resulting in greater cuff volume and pressure compared to LTS-D and PLMA, decreased likelihood of successful insertion on first attempt compared to LTS-D, and greater prevalence of sore throat and dysphagia compared to LTS-D and PLMA, without any significant differences in insertion time.
\end{abstract}

Key words: LTS-D, PLMA, ETC, Airway, Supralaryngeal airway device

Clinical trial registration : NTC \# NCT00581386

\section{Introduction}

During the past decade, several supralaryngeal airway devices have been introduced into clinical practice. These airway devices have gained popularity because of their ease of use and ability to maintain a clear airway without perturbing the trachea [1] While some of these devices were initially dedicated to the operating room [2], most of them have subsequently been granted use in the prehospital and emergency settings, making them the primary device still in place for airway management in major traumas or for patient transport [3-4], and being used transiently before a definitive airway can be established (endotracheal intubation) [5-6].

The Esophageal Tracheal Combitube ${ }^{\mathrm{TM}}$ (ETC, Covidien, Mansfield, MA, USA) a disposable double-lumen supralaryngeal airway device that combines the features of a conventional endotracheal tube with those of an esophageal obturator airway, has been used as the standard airway management tool by paramedics in the prehospital setting, mostly because of high leak pressures, protection of gastric content regurgitation and fast learning curve [4]. However, ETC has been considered to be very uncomfortable for the patient, can lead to esophageal tears, and does not allow fiberoptic control through its airway tube. The Laryngeal Tube ${ }^{\circledR}$ (LTS; VBM Medizintechnik; King Systems, Noblesville, IN) is another supralaryngeal airway device designed to provide an effective seal, similar to the ETC, while providing some advantages [7]. The reported success rate of insertion of and ventilation through LTS ranges from 92-100\% for the earlier prototype and $97-100 \%$ for the latest version, which permits gastric access [8]. Similar to the ETC, LTS allows for an orogastric tube to be passed for gastric drainage and pressure release [9-11]. A disposable version of the LTS is now available, the Laryngeal Tube Suction - Disposable (LTS-D, King Systems, Noblesville, IN, USA).

The present study was designed and begun in 2007 at the time of LTS-D release and inavailability of cohort randomized controlled studies. Our hypothesis related to the effectiveness 
Cattano et al. Journal of Anesthesiology and Clinical Science 2012,

of the LTS-D compared to that of the two standards of the operating room (ProSeal Laryngeal Mask Airway ${ }^{\top M}[$ PLMA], LMA North America, San Diego, CA, USA) and emergency setting (ETC). Few studies have recently been conducted that used similar investigational conditions [7,12-14]. This clinical study has been designed to compare three supralaryngeal devices that have secondary channels (ETC, LTS-D, and PLMA) in the elective operating room setting.

\section{Materials \& Methods}

Two hundred twenty five patients were consecutively screened and enrolled in a randomized controlled prospective study after local institutional review board approval (HSC-MS-04-254). The study was registered at http://www.clinicaltrials.gov/ct2/ show/NCT00581386. Patient consent was obtained both in oral and written form. Seven patients were excluded from the study after having already signed the consent but before the induction of anesthesia, either because the patient withdrew consent $(n=3)$ or the anesthesiologist reconsidered the choice of the airway management technique $(n=4)$. All patients underwent general anesthesia for elective surgery. Patients included in the study were aged 18 to 80 years, had ASA class I - III, Mallampati Class I - II, and BMI $\leq 35 \mathrm{~kg} / \mathrm{m}^{2}$. Patients were excluded from the study if they presented with ASA Class IV or V, Mallampati Class III or IV, emergency status, BMI >35 $\mathrm{kg} / \mathrm{m}^{2}$, were pregnant, had history of gastroesophageal reflux symptoms or treatment, low pulmonary compliance or high pulmonary resistance, pharyngeal or laryngeal pathology, or a known history of difficult intubation. Upon enrollment in the study, patients were randomized to receive ETC, LTS-D, or PLMA by closed assignment envelopes. The randomization list was computer generated and no blocking or stratification was performed.

Only resident anesthesiologists, supervised by attending anesthesiologists, were involved in the placement of the devices. All CA-2 $(n=22)$ and CA-3 $(n=23)$ residents were eligible to participate in the study. Residents received specific training in the use of all three devices (manikin training sessions with three placements using each device) before commencement of the study and again received brief instruction before having the patient moved to the operating room, once the assignment group was revealed. Our institution's residency program has a standard airway management rotation and a dedicated airway management rotation each residency year starting with the CA-2 year.

Once intravenous access was established, all patients were taken to the operating room. Standard ASA monitors including blood pressure (BP) cuff, EKG, and pulse oximeter were applied. Baseline vital signs were obtained and general anesthesia was induced with $1.5-2 \mathrm{mg} / \mathrm{kg}$ propofol. Once adequate mask ventilation was assured, muscle relaxation was achieved with either succinylcholine $1 \mathrm{mg} / \mathrm{kg}$ or rocuronium $0.6 \mathrm{mg} / \mathrm{kg}$. Patient parameters recorded included heart rate, non-invasive $B P$, respiratory rate, peripheral oxygen saturation, end-tidal carbon dioxide concentration, tidal volume, and airway peak pressures. Parameters were recorded at baseline, prior to device insertion, at 1, 2, 3, 4, 5, 10 and 15 minutes after insertion, and at extubation.

Before induction, all patients underwent preoxygenation with $8 \mathrm{~L}$ of oxygen for 3 minutes by face mask as preparation for device insertion. The patient's head and neck were kept in the neutral position, and the designated device was inserted by a resident anesthesiologist using a jaw lift approach. In the event of difficulty with device insertion, the patient's neck was repositioned. The time taken to insert the device was recorded in each instance in all groups. The size of the device chosen was based on manufacturer recommendations. For patients in the LTS-D group, those 4-5 feet tall received a size 3 LTS-D, those 5-6 feet tall received a size 4 LTS-D, and those $\geq 6$ feet tall received a size 5 LTS-D. For patients in the PLMA group, those weighing $50-70 \mathrm{~kg}$ received a size 4 PLMA and those weighing $70-100 \mathrm{~kg}$ received a size 5 PLMA. For patients in the ETC group, those 4- 6 feet tall received a 37 French SA (small adult) ETC, and patients $\geq 6$ feet tall received a 41 French (large adult) ETC.

The cuffs of both the LTS-D and PLMA were initially inflated by recommended manufacturer volumes and then set to an intracuff pressure of $60 \mathrm{~cm} \mathrm{H}_{2} \mathrm{O}$, using a cuff pressure gauge (Kings Systems, Noblesville, IN, USA). When using either the 37 French or 41 French ETC, $40-85 \mathrm{cc}$ of air was used to inflate the \#1 proximal cuffs and $10 \mathrm{cc}$ of air was used to inflate the \#2 distal cuffs. These volumes were titrated until a seal was achieved using the "minimal leakage technique," ensuring it did not exceed $12 \mathrm{cc}$ and $15 \mathrm{cc}$, respectively, in the \#2 distal cuff of the 37 French ETC and 41 French ETC. Ease of insertion was determined by the anesthesiology residents using a 4-point Likert scale ( $1=$ very easy, $2=$ =easy, $3=$ difficult, $4=$ =very difficult). After insertion, all devices were connected to a closed-circuit breathing system. If placement was unsatisfactory as determined by the attending anesthesiologist, placement was reattempted. After 3 failed attempts, no further attempts at supralaryngeal device placement were made, the airway was secured in another manner, and these patients were excluded from the data analysis (Figure 1).

After successful placement, the airway leak pressure was assessed by closing the circuit to $40 \mathrm{~cm} \mathrm{H}_{2} \mathrm{O}$ allowing fresh gas flow to build airway pressure. The pressure at which an audible leak occurred was then recorded. For the LTS-D and PLMA, the airway leak was assessed after cuff pressures were reduced to $60 \mathrm{~cm} \mathrm{H}_{2} \mathrm{O}$ using the dedicated gauge. The anatomic placement of these airway devices was assessed by fiberoptic examination of the glottis in relation to the shaft of the airway device and the view was graded based on a standardized 4-point scoring system of whether the entire glottis was visible and if the epiglottis obscured the view $(1=$ glottis completely visible, 2 = glottis partially visible, 3 = glottis partially covered by epiglottis, $4=$ only epiglottis visible) [15]. Upon completion of the patient's surgery, the 


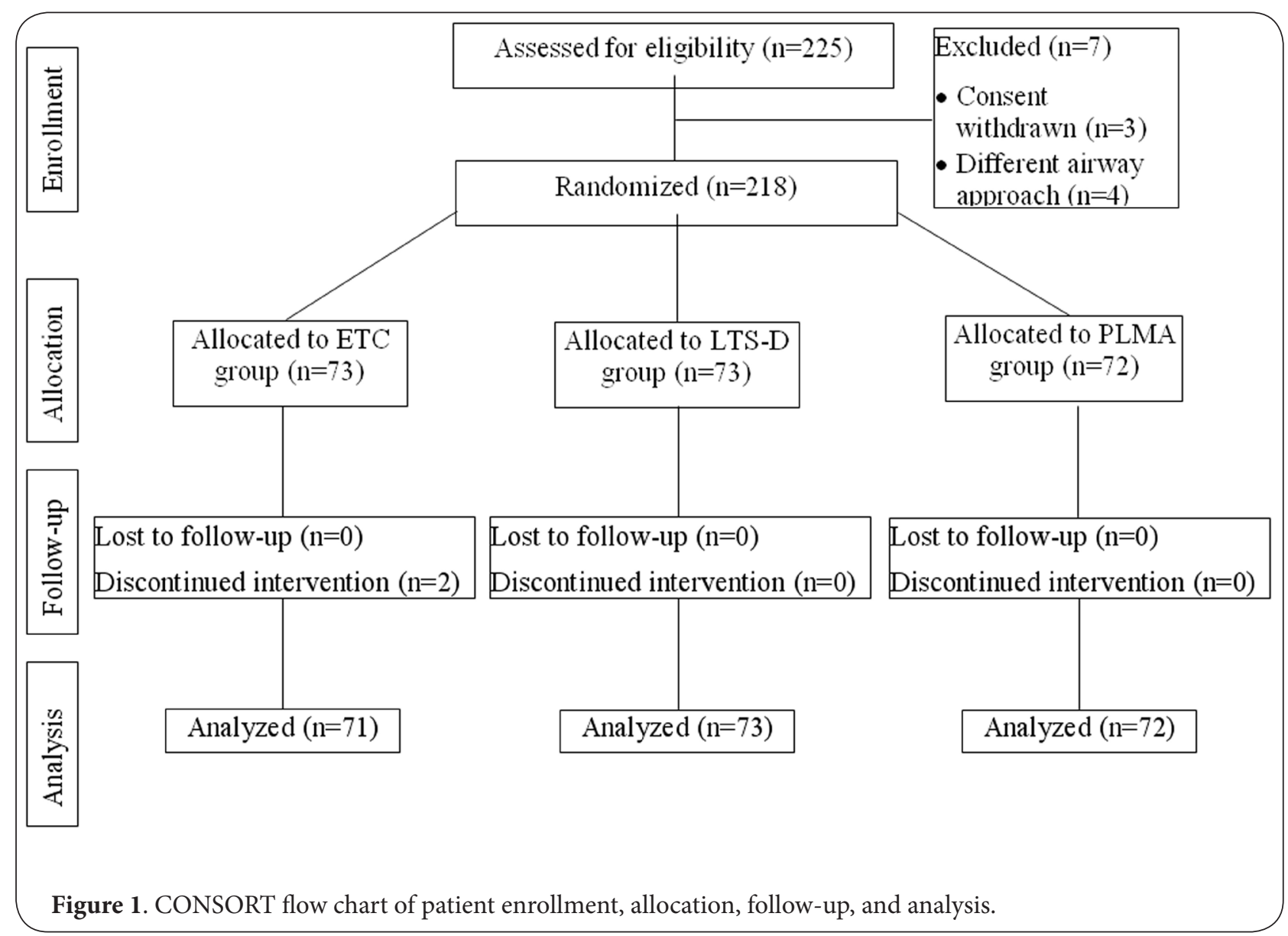

airway device was examined for any evidence of blood. Additionally, all patients were interviewed at 2 and 24 hours postoperatively in order to assess for the presence of sore throat, hoarseness, and dysphagia using a 4-point Likert scale ( $1=$ normal, $2=$ mild, $3=$ moderate, $4=$ severe).

Statistical analysis of the data was conducted in Stata (Statacorp, College Station, TX). Data comparison was performed by Student's t-test (continuous variables) and chi-square test (categorical variables). Power analysis determined that 68 patients needed to be enrolled in each group, considering an alpha of 0.05 and power of $80 \%$. Data are presented as mean \pm standard deviation or percentage.

\section{Results}

Sixteen CA-2 (72.7\%) and 14 CA-3 (60.9\%) residents participated in the study. A total of 216 patients were analyzed among the ETC $(n=71)$, LTS-D $(n=73)$, and PLMA ( $n=72)$ groups. The demographic data for each group is summarized in Table 1. The operative duration and the sizes of each device used across the groups were comparable. Additionally, heart rate, mean blood pressure, and peak airway pressure were similar for patients in each group.

The ETC, LTS-D, and PLMA groups demonstrated significant
Table 1. Patient Demographics

\begin{tabular}{|c|c|c|c|c|}
\hline Parameter & $\operatorname{ETC}(n=71)$ & LTS-D (n=73) & $\begin{array}{l}\text { PLMA } \\
(n=72)\end{array}$ & $\mathrm{p}$-value \\
\hline Sex (Male, \%) & 49 (69.0\%) & $50(68.5 \%)$ & 55 (76.4\%) & NS \\
\hline Age (years) & $39.5 \pm 13.8$ & $41.8 \pm 15.0$ & $40.1 \pm 13.7$ & NS \\
\hline BMI (kg/m2) & $\begin{array}{l}(n=69) \\
26.8 \pm 4.5\end{array}$ & $\begin{array}{l}(n=70) \\
27.2 \pm 4.9\end{array}$ & $\begin{array}{l}(n=68) \\
27.5 \pm 4.5\end{array}$ & NS \\
\hline ASA (I/II/III) & $\begin{array}{l}(n=69) \\
23 / 39 / 7\end{array}$ & $\begin{array}{l}(n=68) \\
23 / 36 / 9\end{array}$ & $\begin{array}{l}(n=71) \\
18 / 46 / 7\end{array}$ & NS \\
\hline $\begin{array}{l}\text { Mallampati (I/ } \\
\text { II/III) }\end{array}$ & $\begin{array}{l}(n=69) \\
32 / 34 / 3\end{array}$ & $\begin{array}{l}(n=66) \\
32 / 28 / 6\end{array}$ & $\begin{array}{l}(n=70) \\
35 / 32 / 3\end{array}$ & NS \\
\hline $\begin{array}{l}\text { Device size ( } 37 \\
\text { Fr/41 Fr for ETC; } \\
3 / 4 / 5 \text { for LTS-D } \\
\text { and PLMA) }\end{array}$ & $61 / 10$ & $\begin{array}{l}(n=71) \\
1 / 51 / 19\end{array}$ & $0 / 22 / 50$ & $\mathrm{~N} / \mathrm{A}$ \\
\hline $\begin{array}{l}\text { Mouth opening } \\
(1 / 2 / 3 / 4)\end{array}$ & $\begin{array}{l}(n=60) \\
0 / 4 / 19 / 37\end{array}$ & $\begin{array}{l}(n=59) \\
1 / 12 / 19 / 27\end{array}$ & $\begin{array}{l}(n=62) \\
0 / 6 / 31 / 25\end{array}$ & $p=0.034$ \\
\hline $\begin{array}{l}\text { Neck Size (short / } \\
\text { average / thick) }\end{array}$ & $3 / 66 / 2$ & $(n=71) 5 / 58 / 8$ & $4 / 60 / 8$ & NS \\
\hline
\end{tabular}

ASA = American Society of Anesthesiologists, BMI = body mass index, ETC = Esophageal Tracheal Combitube ${ }^{\text {Tx }}$, LTS-D = Disposable Laryngeal Tube Suction $^{\mathrm{TM}}, \mathrm{N} / \mathrm{A}=$ not applicable, NS = not significant, PLMA $=$ ProSeal Laryngeal Mask Airway ${ }^{\mathrm{TM}}$ 
Cattano et al. Journal of Anesthesiology and Clinical Science 2012,

http://www.hoajonline.com/journals/pdf/2049-9752-1-8.pdf

doi: $10.7243 / 2049-9752-1-8$

Table 2. Differences in Device Measurements and Patient Discomfort

\begin{tabular}{|c|c|c|c|c|}
\hline Parameter & $\operatorname{ETC}(n=71)$ & LTS-D ( $n=73)$ & PLMA (n=72) & p-value \\
\hline No. Attempts $(1 / 2 / 3)$ & $50 / 14 / 7$ & $65 / 6 / 2$ & $52 / 15 / 5$ & NS \\
\hline Time for successful placement (sec) & $(n=63) 30.8 \pm 23.3$ & $(n=67) 30.9 \pm 18.7$ & $(n=63) 30.6 \pm 31.5$ & NS \\
\hline Cuff Volume (cc) & $(n=63) 84.0 \pm 9.1$ & $(n=68) 64.8 \pm 12.4$ & $(n=67) 31.3 \pm 17.9$ & $p<0.00001^{d, e, f}$ \\
\hline Cuff Pressure $\left(\mathrm{cm} \mathrm{H}_{2} \mathrm{O}\right)$ & $(n=52) 284.2 \pm 63.0$ & $(n=69) 72.0 \pm 15.7$ & $(n=67) 72.3 \pm 21.7$ & $p<0.00001^{d, e}$ \\
\hline Leak Pressure $\left(\mathrm{cm} \mathrm{H}_{2} \mathrm{O}\right)$ & $(n=61) 23.7 \pm 5.2$ & $(n=66) 25.9 \pm 4.6$ & $(n=66) 24.4 \pm 5.1$ & NS \\
\hline Fiberoptic view $(1 / 2 / 3 / 4)^{a}$ & - & $(n=62) 13 / 19 / 6 / 24$ & $(n=64) 7 / 26 / 23 / 8$ & $p<0.0001$ \\
\hline Insertion success (\%) & $64(90.1 \%)$ & 69 (94.5\%) & 67 (93.1\%) & NS \\
\hline Insertion time (sec) & $(n=66) 50.8 \pm 52.6$ & $(n=70) 49.4 \pm 89.1$ & $(n=69) 62.7 \pm 80.7$ & NS \\
\hline Duration (sec) & $(n=49) 77.4 \pm 52.4$ & $(n=51) 78.4 \pm 47.0$ & $(n=52) 82.0 \pm 53.8$ & NS \\
\hline Ease of insertion $(1 / 2 / 3 / 4)^{b}$ & $(n=44) 14 / 23 / 5 / 2$ & $(n=49) 20 / 26 / 3 / 0$ & $(n=49) 20 / 25 / 3 / 1$ & NS \\
\hline Sore throat at 2 hours $(1 / 2 / 3 / 4)^{c} \mathrm{c}$ & $(n=61) 21 / 23 / 6 / 11$ & $(n=60) 32 / 21 / 6 / 1$ & $(n=63) 38 / 22 / 2 / 1$ & $p=0.001$ \\
\hline Hoarseness at 2 hours $(1 / 2 / 3 / 4)^{c}$ & $(n=61) 47 / 9 / 4 / 1$ & $(n=60) 48 / 9 / 2 / 1$ & $(n=63) 51 / 10 / 2 / 0$ & NS \\
\hline Dysphagia at 2 hours $(1 / 2 / 3 / 4)^{c}$ & $(n=61) 40 / 6 / 7 / 8$ & $(n=60) 47 / 9 / 3 / 1$ & $(n=63) 47 / 14 / 2 / 0$ & $p=0.003$ \\
\hline Sore throat at 24 hours $(1 / 2 / 3 / 4)^{c}$ & $(n=59) 21 / 16 / 15 / 7$ & $(n=54) 34 / 17 / 2 / 1$ & $(n=54) 40 / 12 / 2 / 0$ & $p<0.0001$ \\
\hline Hoarseness at 24 hours $(1 / 2 / 3 / 4)^{c}$ & $(n=59) 44 / 9 / 4 / 2$ & $(n=54) 46 / 7 / 1 / 0$ & $(n=54) 48 / 6 / 0 / 0$ & NS \\
\hline Dysphagia at 24 hours $(1 / 2 / 3 / 4)^{c}$ & $(n=59) 32 / 11 / 12 / 4$ & $(n=54) 46 / 7 / 0 / 1$ & $(n=54) 47 / 6 / 1 / 0$ & $\mathrm{p}<0.0001$ \\
\hline
\end{tabular}

${ }^{a} 1$ = glottis completely visible, 2 = glottis partially visible, 3 = glottis partially covered by epiglottis, 4 = only epiglottis visible. ${ }^{b} 1=$ very easy, $2=e a s y, 3=$ difficult, $4=$ very difficult. ${ }^{~} 1=$ normal, $2=$ mild, $3=$ moderate, $4=$ severe. ${ }^{d}$ ETC vs. LTSD. ${ }^{e}$ ETC vs.

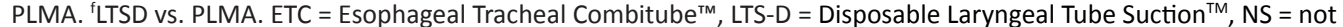
significant, PLMA $=$ ProSeal Laryngeal Mask Airway ${ }^{\top M}$

differences in successful insertion on first attempt $(70.0 \%$, $89.0 \%$, and $72.2 \%$, respectively), $\mathrm{p}=0.012$ (Table 2 ). The time taken for successful placement did not significantly differ among the three devices. There was no significant difference in successful insertion rate among the ETC (90.1\%), LTS-D (94.5\%), and PLMA (93.1\%) groups, $\mathrm{p}=0.6$. The fiberoptic airway view after device placement was recorded in zero patients in the ETC group, $62 / 73$ patients (85\%) in the LTS-D group, and $64 / 72$ patients (89\%) in the PLMA group. The fiberoptic view was rated as 1, 2, or 3 (out of 4 ) in 38/62 (61.3\%) of patients in the LTS-D group and in 56/64 (87.5\%) of patients in the PLMA group, $p=0.001$.

Cuff pressure was significantly greater in the ETC group (284.2 $\pm 63.0 \mathrm{~cm} \mathrm{H}_{2} \mathrm{O}$ ) compared to each of the LTS-D (72.0 \pm 15.7 $\left.\mathrm{cm} \mathrm{H}_{2} \mathrm{O}\right)$, and PLMA $\left(72.3 \pm 21.7 \mathrm{~cm} \mathrm{H}_{2} \mathrm{O}\right)$ groups, $\mathrm{p}<0.00001$. Cuff volume was significantly greater in the ETC group (84.0 \pm 9.1 cC) compared to each of the LTS-D $(64.8 \pm 12.4 \mathrm{cC})$, and PLMA $(31.3 \pm 17.9 \mathrm{cc})$ groups, $\mathrm{p}<0.00001$, and was significantly greater in the LTS-D group compared to the PLMA group, $p<0.00001$. Leak pressure was comparable among the ETC $(23.7 \pm 5.2 \mathrm{~cm}$ $\left.\mathrm{H}_{2} \mathrm{O}\right)$, LTS-D (25.9 $\left.\pm 4.6 \mathrm{~cm} \mathrm{H}_{2} \mathrm{O}\right)$, and PLMA (24.4 $\left.\pm 5.1 \mathrm{~cm} \mathrm{H}_{2} \mathrm{O}\right)$ groups. The ease of device insertion was determined to be "very easy" or "easy" in $81.8 \%$ of ETC cases, $93.9 \%$ of LTS-D cases, and $91.8 \%$ of PLMA cases, $\mathrm{p}=0.13$.

Prevalence of severe sore throat and dysphagia was greater in the ETC group compared to the other groups, both at 2 hours $(p<0.003)$ and 24 hours $(p<0.0001)$ after securing the airway (Figure 2).

\section{Discussion}

This randomized controlled trial evaluated three supralaryngeal airway management devices with secondary lumens (ETC, LTS-D, and PLMA) in regards to ease of insertion, duration of successful placement, leak pressures, number of attempts required for successful insertion, and post-anesthesia patient discomfort. Previous studies have also reported on comparisons among these three devices [7,12-14].

The current results suggest that all three devices can be successfully utilized in adult patients undergoing elective surgery. The devices were comparable in regards to leak pressure, insertion success rate, insertion time, and ease of insertion. However, the ETC device significantly increased the incidence of dysphagia and sore throat at 2 hours and 24 hours post-insertion compared to each of the other two devices. Overall, there were no hemodynamic differences noted among the groups. Similar findings were reported for minor elective surgical procedures by Gaitini et al. [5], in which LTS and PLMA were compared. They found that the devices were comparable in terms of insertion success rate, oxygenation, and ventilation [5]. The current findings also concur with those previously reported by Bein et al., in which both the LTS-D and PLMA devices demonstrated similar leak pressures and low pharyngeal morbidity [12]. Although the ETC device is not routinely used in the operating room setting, the findings of no significant differences in regards to number of attempts and time for successful placement, fiberoptic view, insertion success, and ease of insertion when 


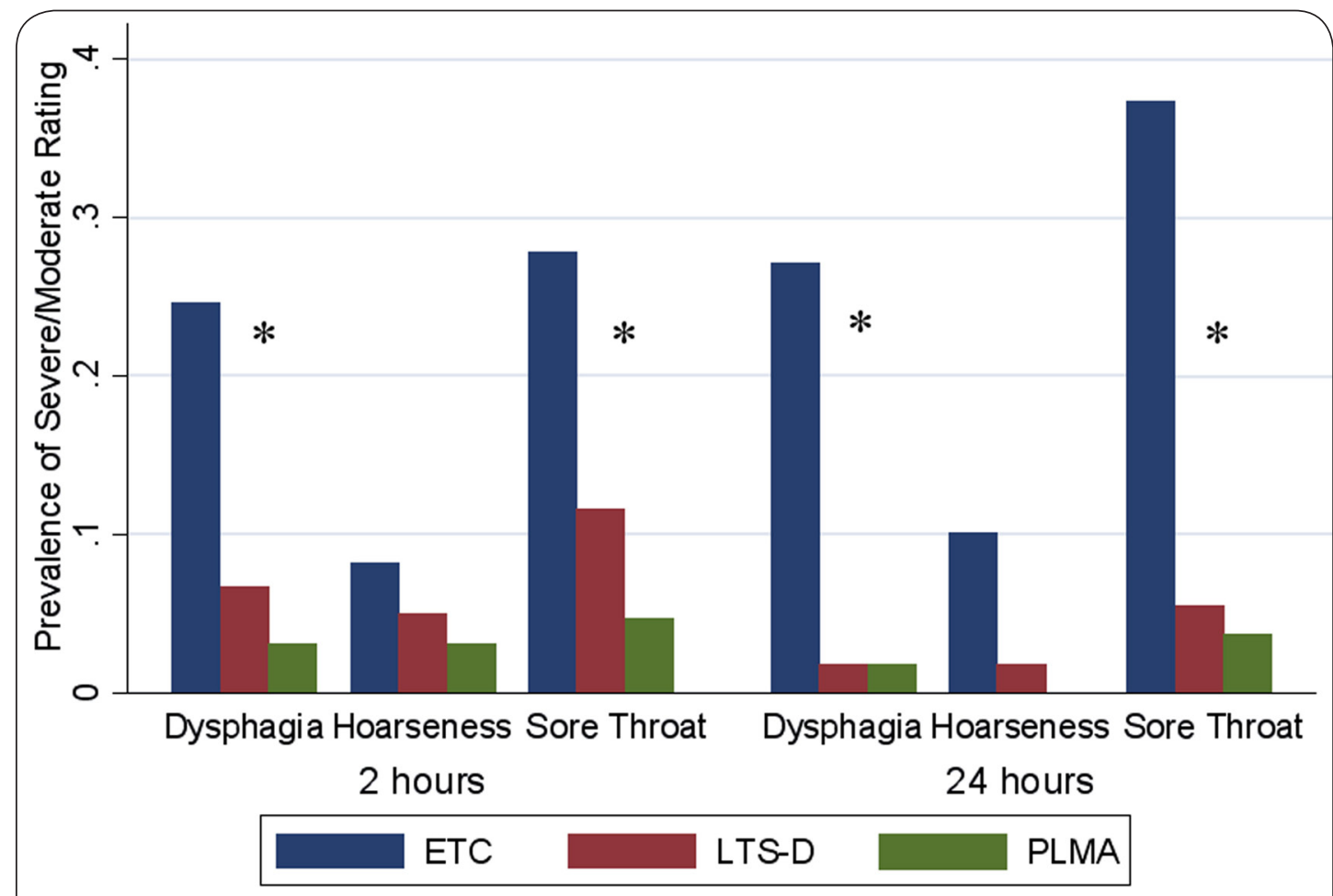

Figure 2. Prevalence of severe/moderate dysphagia, hoarseness, and sore throat at 2 hours and 24 hours after supralaryngeal device insertion. ${ }^{\star}$ indicates $\mathrm{p}<0.003$.

compared to the other devices provides support for its use by emergency responders, with the trade-off of increased incidence of sore throat and dysphagia.

This study demonstrates the relative clinical superiority of the LTS-D, compared to the PLMA and ETC, in some areas. When compared to the PLMA and ETC, the LTS-D resulted in a significantly higher success of insertion on first attempt. Kikuchi et al. reported comparable insertion times for PLMA and LTSII devices, but in contrast to the findings of the current study, found LTSII to have significantly reduced first time success rate and leak pressures compared to PLMA [14]. The reduced first time success rate was attributed to the LTSII entering the tracheal inlet instead of the esophagus in 5 of $50(10 \%)$ patients [14].

The fiberoptic view rating of "very difficult" on the fourpoint scale was significantly more prevalent in the LTS-D group compared to the PLMA group. This is consistent with the anatomical design of the PLMA device that allows it to fit around the larynx, whereas the LTS-D device is a straight conduit. In addition, the distance between the airway opening and the tip of the airway device may affect the exit of the fiberoptic scope at difference airway levels. The presence of a glottic view in $61.3 \%$ of patients in the LTS-D group in the current study is comparable to the findings of Mihai et al., who reported that the glottis was fiberoptically visible in $51 \%$ of patients whose airway was secure with the LTSII device [16]. Non-visualization of the vocal cords in $38.7 \%$ of LTS-D patients and $12.5 \%$ of PLMA patients may have been due to the different diameter of the devices. Differences in insertion technique may have also contributed to vocal cord visualization, as the PLMA is inserted with a finger or introducer technique whereas the LTS-D is not.

Consistent with findings by Oczenski et al., [13], and those previously mentioned $[\mathbf{7 , 1 2 , 1 4 ]}$, we found that LTS-D and PLMA resulted in a significantly reduced prevalence of dysphagia and sore throat compared to ETC. In other studies [12-13], ETC also exhibited a higher rate of other complications, including oral trauma and oropharyngeal mucosal hematoma, which were attributed to the rigidity of the tube and its higher oropharyngeal cuff pressures. However, oral direct injury related to the ETC device was not observed in the current study. The differences in cuff pressure and volume observed in this study were not suprising because the three supralaryngeal devices have different shapes and methods of ventilation.

The findings of this study must be considered in the context of its limitations. Anesthesiologists supervising the device insertion were not blinded and were responsible for the study conduct and outcomes. This potential bias was mitigated by employing anesthesiology residents as the testing personnel, in order to represent less experienced users. User-dependent 
variation among the residents may explain some of the differences between the current findings and those of previous studies. Second, the three supralaryngeal airway devices that were investigated are not frequently used in the operating room for routine surgical cases; however, they have wide applicability in life-threatening situations when non-anesthesia trained personnel may need to secure an airway. Third, as compared to previous studies, the leak pressures in this study were not as high as those reported in most previous studies. This could be due to performing the measurement of the leak pressures at end tidal $\mathrm{CO}_{2}$, using relatively inexperienced users, and not re-adjusting the devices. Fourth, the use of routine muscle relaxation after adequately securing the airway may have altered the cuff pressure, leak pressure, and respiratory system peak pressure measurements.

\section{Conclusions}

In conclusion, the LTS-D was relatively superior to the ETC and PLMA for airway management in adult patients presenting for routine surgical procedures, in regards to success of insertion on first attempt. Cuff pressure was significantly greater in the ETC group compared to each of the LTS-D and PLMA groups. Cuff volume was significantly greater in the ETC group compared to each of the LTS-D and PLMA groups, and was significantly greater in the LTS-D group compared to the PLMA group. The ETC device also resulted in significantly increased pharyngeal morbidity compared to each of the LTS-D and PLMA devices.

\section{Acknowledgement}

The authors thank Vineela Maddukuri, MD and Olga Pawelek, MD for assistance with execution of the study, Robert $\mathrm{E}$.

Lasky, PhD for assistance with statistical analysis, and Sebas-

tian G. Russo, MD for critical feedback on the manuscript.

Conflict of Interest

Dr. Hagberg is a consultant for Covidien (USA, manufacturer of Esophageal Tracheal CombitubeTM [ETC]) and AMBU (USA), and received research funding from AMBU (USA) and LMA North America (USA, manufacturer of ProSeal Laryngeal Mask AirwayTM [PLMA]). Dr. Hagberg is also on the speaker's bureau for AMBU (USA) and LMA North America (USA). None of these companies provided financial interest in the conduct of this study and Dr. Hagberg's relationship with these companies were unrelated to the current study. Dr. Cattano, Dr. Ferrario, Dr. Patel, Dr. Normand, and Ms. Seitan do not have a direct financial relation with the commercial identities mentioned in this manuscript that might lead to a conflict of interest.

Funding disclosure

LTS-D King Systems (Noblesville, IN, USA) provided both financial and material support for the conduct of this study. The company did not have any role in the drafting, editing, or approval of this manuscript.

Publication history

Received: 19-June-2012 Revised: 11-July-2012

Accepted: 23/7/2012 Published: 08-Aug-2012

\section{References}

1. Marco CA, Marco AP: Airway adjuncts. Emerg Med Clin North Am 2008; 26;(4.);1015-27, x. | Article | PubMed

2. Brain Al, McGhee TD, McAteer EJ, Thomas A, Abu-Saad MA, Bushman
JA: The laryngeal mask airway. Development and preliminary trials of a new type of airway. Anaesthesia 1985; 40;(4.);356-61. | Article | PubMed

3. Thierbach AR, Piepho T, Maybauer M: The EasyTube for airway management in emergencies. Prehosp Emerg Care 2005; 9;(4.);445-8. | Article I PubMed

4. Agro F, Frass M, Benumof JL, Krafft P: Current status of the Combitube: a review of the literature. J Clin Anesth 2002; 14;(4.);307-14. | Article | PubMed

5. Gaitini LA, Vaida SJ, Somri M, Yanovski B, Ben-David B, Hagberg CA: A randomized controlled trial comparing the ProSeal Laryngeal Mask Airway with the Laryngeal Tube Suction in mechanically ventilated patients. Anesthesiology 2004; 101;(2.);316-20. | Article | PubMed

6. Lam NC, Hagberg CA, Bassili LM: Use of the video laryngoscopy for Combitube exchange in a difficult airway. $J$ Clin Anesth 2009; 21;(4.);294-6. | Article | PubMed

7. Cavus E, Deitmer W, Francksen H, Serocki G, Bein B, Scholz J, et al.: Laryngeal tube $S$ II, ProSeal laryngeal mask, and EasyTube during elective surgery: a randomized controlled comparison with the endotracheal tube in nontrained professionals. Eur J Anaesthesiol 2009; 26;(9.);7305. | Article | PubMed

8. Asai T, Shingu K: The laryngeal tube. Br J Anaesth 2005; 95;(6.);729-36. | Article | PubMed

9. Dorges $\mathrm{V}$, Ocker H, Steinfath M. The Laryngeal Tube S: A new airway device for lung ventilation and free gastric drainage. Anesthesiology 2002; 96: A1188. | Abstract

10. Genzwuerker HV, Roth H, Rothhaas A, Finteis T, Schmeck J. Comparison of the LMA-ProSeal and LTS for ventilation during laparoscopic gynaecological surgery. Anesthesiology 2003; 99:A1194. | Abstract

11. Dorges V, Carstensen S, Bein B, Claus L, Steinfath M. The newly developed Laryngeal Tube $S-A$ comparison with the Combitube during routine surgical procedures. Anesthesiology 2003; 99:A1243. | Abstract

12. Bein B, Carstensen S, Gleim M, Claus L, Tonner PH, Steinfath M, et al.: A comparison of the proseal laryngeal mask airway, the laryngeal tube $S$ and the oesophageal-tracheal combitube during routine surgical procedures. Eur J Anaesthesiol 2005; 22;(5.);341-6. | Article I PubMed

13. Oczenski W, Krenn H, Dahaba AA, Binder M, El-Schahawi-Kienzl I, Kohout $S$, et al.: Complications following the use of the Combitube, tracheal tube and laryngeal mask airway. Anaesthesia 1999; 54;(12.);1161-5. I Article I PubMed

14. Kikuchi T, Kamiya Y, Ohtsuka T, Miki T, Goto T: Randomized prospective study comparing the laryngeal tube suction II with the ProSeal laryngeal mask airway in anesthetized and paralyzed patients. Anesthesiology 2008; 109;(1.);54-60. | Article | PubMed

15. Cook TM, Hardy R, McKinstry C, Twigg S: Use of the laryngeal tube as a dedicated airway during tracheal intubation. BrJ Anaesth 2003; 90;(3.);397-9; author reply -9. | Article | PubMed

16. Brimacombe J, Keller C: Aspiration of gastric contents during use of a ProSeal laryngeal mask airway secondary to unidentified foldover malposition. Anesth Analg 2003; 97;(4.);1192-4, table of contents. | Article | PubMed

17. Mihai $R$, Knottenbelt $G$, Cook TM: Evaluation of the revised laryngeal tube suction: the laryngeal tube suction II in 100 patients. Br J Anaesth 2007; 99;(5.);734-9. | Article | PubMed

\section{Citation:}

Cattano D, Ferrario L, Patel C B, Normand K C, Seitan $C$ and Hagberg C A: Laryngeal Tube Suction-D, Combitube, and Proseal Laryngeal Mask Airway: Randomized Clinical Trial. journal of Anesthesiology and Clinical Science 2012, 1:8. http://dx.doi.org/10.7243/2049-9752-1-8 